\title{
MENINGKATKAN KUALITAS PELAYANAN RUMAH SAKIT JIWA MELALUI ANALISIS KINERJA PERAWAT DENGAN METODE BALANCE SCORECARD
}

\author{
Imas Masriah ${ }^{1}$, Ongkong Sion² \\ 'Universitas Pamulang, Banten \\ ${ }^{2}$ RSJ Anmarsu Hospice, Jawa Barat \\ Email : dosen02036@unpam.ac.id, Imanuel_ongkong@yahoo.com
}

\begin{abstract}
ABSTRAK
Penelitian ini bertujuan untuk menganalisis kinerja perawat dan kualitas pelayanan pada Rumah Sakit Jiwa Anmarsu Hospice Care. Metode penelitian yang digunakan pendekatan kualitatif dekskriptif, dengan pengumpulan sumber data secara primer melalui wawancara kepada Direktur Utama RSJ Anmarsu Hospice Care, Ketua RSJ Anmarsu Hospice Care, Bagian Keuangan, dan dua orang perawat sekunder yang didapatkan dari telaah dokumen peningkatan kualitas karyawan. Adapun analisis yang digunakan yaitu teknik analilsis isi (content analysis) dengan menggunakan alat ukur Balance Scorecard. Hasil penelitian ini terdiri dari tiga bagian yaitu bagian pertama dengan pendekatan terhadap keseluruhan pengukuran didapatkan 23 poin $\times 2=46$ poin, bagian kedua dengan pendekatan jenis tolak ukur spesifik terhadap organisasi didapatkan 140 poin, dan bagian ketiga dengan pendekatan pelaporan dan analisis data didapatkan 48 poin $\times 2=96$ poin. Berdasarkan hasil dari perhitungan skor secara keseluruhaan, didapatkan jumlah total nilai 282 poin yang berarti Rumah Sakit Jiwa Anamrsu Hospice Care telah memiliki pendekatan yang sangat baik dalam mengukur kinerja organisasi.
\end{abstract}

Kata Kunci : Analisis Kinerja Perawat, Kualitas Pelayanan, Balanced Scorecard

\begin{abstract}
This study aims to analyze the performance of nurses and service quality at the Anmarsu Hospice Care Mental Hospital. The research method used is a descriptive qualitative approach, by collecting primary data sources through interviews with the Managing Director of RSJ Anmarsu Hospice Care, the Chairperson of the Anmarsu Hospice Care Hospital, the Finance Department, and two secondary nurses obtained from reviewing employee quality improvement documents. The analysis used is the content analysis technique using the Balanced Scorecard measuring instrument. The results of this study consisted of three parts, namely the first part with an approach to overall measurement obtained 23 points $\times 2=46$ points, the second part with a specific type of measurement approach to the organization obtained 140 points, and the third part with a reporting approach and data analysis obtained 48 points $\times 2=96$ points. Based on the results of the overall score calculation, a total score of 282 points is obtained, which means that the Anamrsu Hospice Care Mental Hospital has a very good approach in measuring organizational performance.
\end{abstract}

Keywords: Nurse Performance Analysis, Service Quality, Balanced Scorecard

\section{PENDAHULUAN}

Rumah sakit adalah suatu organisasi yang dilakukan oleh tenaga medis professional yang terorganisir baik dari sarana prasarana kedokteran yang permanen, pelayanan kedokteran, asuhan keperawatan yang berkesinambungan, diagnosis serta pengobatan penyakit yang diderita oleh pasien. Rumah sakit mempunyai berbagaai macam jenis pelayanan kesehataan yang dapat di unggulkan untuk mempertahankan loyalitas pasien. Salah satu jenis pelayanan kesehataan yang ada di rumah sakit adalah pelayanan rawat inap, pelayanan rawat inap merupakan salah satu unit 
pelayanan di rumah sakit yang memberikan pelayanan secara komprehensif untuk membantu menyelesaikan masalah yang dialami oleh pasien, di mana unit rawat inap merupakan salah satu renevew center rumah sakit sehingga tingkat kepuasan pelanggan atau pasien terhadap pelayanan bisa di gunakan sebagai indikator mutu pelayanan [1].

Saat ini RS merupakan lahan bisnis yang sedang menjadi trend, hal ini terjadi akibat dari masuknya investor asing, perkembangan populasi kelas menegah atas, membaiknya tingkat pendapatan per-kapita, dan semakin kritisnya masyarakat dalam menjaga kesehatan serta memilih tempat untuk berobat.

Kondisi ini memperlihatkan kebutuhan akan layanan RS yang memutus semakin meningkatkan seiring dengan semakin membaiknya perekonomian dan derajat kesehatan masyarakat. Dalam beberapa tahun belakangan ini, industri RS Indonesia telah mengalami perkembangan yang cukup berarti dengan diterbitkannya berbagai peraturan dan perundang-undangan yang bertujuan untuk mendorong investasi dan menciptakan kondisi bisnis dan jasa RS yang lebih baik. Terbukti tidak hanya pemerintah yang memang berkewajiban menyediakan jasa layanan kesehatan kepada masyarakat, para pelaku bisnis pun kini semakin aktif berinvestasi di industri RS Indonesia. Hal inilah yang mendorong bermunculannya RS swasta baru dalam kurun waktu beberapa tahun belakangan ini.

Menjamurnya beberapa rumah sakit swasta baru memunculkan persaingan diantara rumah sakit dalam memperebutkan pasien, untuk dapat memenangkan persaingan, maka rumah sakit harus mempunyai keunggulan kompetitif dibandingkan rumah sakit lainnya. Sumber daya alat dan prasarana yang lain memungkinkan untuk ditiru dan juga dipunyai oleh rumah sakit lain, tetapi tidak demikian dengan sumber daya manusia. Sumber daya manusia merupakan salah satu keunggulan yang seharusnya diciptakan, terus di kembangkan dan di pertahankan [2].

Seperti industri jasa lainnya, industri rumah sakit adalah jenis industri yang menggunakan banyak sumber daya manusia. Sumber daya manusia merupakan salah satu tiang organisasi, yang merupakan motor penggerak roda organisasi dalam upaya mewujutkan visi dan misinya [3]. Karenanya harus dipastikan sumber daya ini dikelola dengan sebaik mungkin agar mampu memberi kontribusi secara optimal [4].

Hal lain yang membuat peranan tenaga manusia menjadi penting adalah perannya dalam memproduksi jasa. Di rumah sakit tidak dimungkinkan untuk memproduksi sebuah jasa kemudian disimpan dan baru digunakan kemudian hari di dalam rumah sakit produksi dan komsumsinya berjalan secara simultan. Interaksi antara pemberi jasa dan komsumen merupakan bagian integral dari pengelolaan sebuah rumah sakit.

Rumah sakit merupakan organisasi pelayanan jasa yang mempunyai kespesifikan dalam hal SDM, sarana prasarana dan peralatan yang dipakai sering rumah sakit dikatakan sebagai organisasi yang padat modal, padat sumber daya manusia, padat teknologi dan ilmu pengetahuan serta padat regulasi. Padat modal karena rumah sakit memerlukan investasi yang tinggi yang memenuhi persyaratan yang ada, padat sumber daya manusia karena di dalam rumah sakit pasti terdapat berbagai profesi dan jumlah karyawan yang banyak. Padat tekologi dan ilmu pengetahuan karena di dalam rumah sakit terdapat peralatan-peralatan yang meningkat berkenaan dengan syarat-syarat pelaksanaan di rumah sakit.

Jasa pelayanan kesehatan terus mengalami perubahan beberapa dekade terakhir diakibatkan oleh kemajuan teknologi, kemudian mendapatkan informasi, bentukbentuk organisasi baru dalam jasa pelayanan kesehatan dan metode pembayaran baru. Tetapi perubahan itu tidak merubah konsumen dari jasa pelayanan kesehatan. Dimana konsumen dari organisasi penyedia jasa pelayanan kesehatan adalah manusia, terlepas dari semua perubahan dalam penyediaan jasa pelayanan baik 
secara pembayaran, jenis pelayanan baik preventif, kuratif, rehabilitatif atau pun diagnostik, konsumennya adalah tetap manusia [5].

Sumber daya manusia di rumah sakit terdiri dari multi profesi yang terdiri dari tenaga kesehatan yang meliputi medis (dokter), paramedis (perawat) dan paramedis non keperawatan yaitu apoteker, analisis kesehatan, asisten apoteker, ahli gizi, fisioterapi, radiologi, perekam medis dan tenaga non kesehatan yaitu bagian keuangan, atministrasi, personalia, dan lain-lain. Kualitas dari masing-masing profesi tersebut tentunya haruslah menjadi fokus perhatian departemen SDM, Salah satu strategi untuk meningkatkan kualitas adalah melalui mekanisme penilaian kinerja karyawan yang efektif karena tujuan dari penilaian kinerja adalah untuk memotivasi karyawan dan meningkatkan kinerja $[6,7]$.

Hasil dari penilaian kinerja dapat digunakan untuk melihat perkembangan perusahaan, sasaran penilaian kinerja adalah kecakapan, kemampuan karyawan dalam melaksanakan suatu pekerjaan atau tugas yang di evaluasi dengan menggunakan tolak ukur tertentu secara obyektif dan dilakukan secara berkala [8].

Sementara itu bagi karyawan penilaian kinerja dapat digunakan untuk melihat sejauh mana prestasi mereka dan seberapa jauh dari standar yang ditetapkan perusahaan, Oleh karena itu penilaian kinerja yang efektif memerlukan adanya umpan balik [9].

Perusahaan tidak cukup hanya memiliki sistem penilaian kinerja, tetapi sistem penilaian tersebut haruslah efektif, diterima, dapat digunakan dengan baik [10]. Dengan begitu penilaian kinerja dapat mengidentifikasikan apa yang diperlukan untuk meningkatkan kualitas sumber daya manusia yang berhubungan dengan analisis pekerjaan dan design, struktur, penempatan, pelatihan, pengembangan, perencanaan karir [11].

Penilaian kinerja digunakan untuk menilai hasil karya karyawan dalam organisasi melalui sebuah instrument penilaian kinerja [12]. Pendapat lain mengemukakan kinerja bukanlah hanya sebatas apa yang dihasilkan seseorang, tetapi juga bagaimana caranya menghasilkan. Kondisi kerja karyawan salah satunya dapat dilihat dengan menggunakan Tools penilaian kinerja. Penilaian kinerja memiliki beberapa pengaruh terhadap fungsi sumber daya manusia. Penilaian kinerja dapat mengarahkan untuk dapat mendesign ulang suatu pekerjaan, memberikan informasi kepada manager atau kepada atasan tentang efektifitas sumber rekrutmen, seleksi, kriteria, dan prosedur. Penilaian kinerja juga dapat memberikan informasi mengenai kebutuhan efektifitas dari pelatihan dan pengembangan karyawan dan dapat memberikan informasi mengenai design kompensasi karyawan [13].

Tingginya angka turn over pada RS. Anmarsu Hospice Care Gunung Sindur Bogor disebabkan oleh rendahnya kompensasi yang diterima oleh karyawan. Berdasarkan hasil pengamatan yang penulis lakukan mengenai sistem penilaian kinerja selama bekerja disini, didapatkan bahwa dengan SDM yang bisa dikatakan jauh dari standar kelengkapan suatu RS, RS Anmarsu ini masih dapat beroperasional dengan baik. Selain itu penulis juga tertarik untuk mengetahui bagaimana RS Anmarsu ini melakukan penilaian kinerja terhadap SDM nya, karena berdasarkan pengamatan selama bekerja ini, didapatkan masih ada SDM yang tidak disiplin karena tidak diberlakukannya sistem reward dan punishment, didapatkan juga ada beberapa SDM yang mengeluh mengenai sistem operasional dan SOP yang selalu berubahubah, ada pula SDM. Selain itu penulis juga tertarik untuk mengetahui bagaimana kualitas pelayanan yang ada di RS Anmarsu selama ini, dan apakah dengan sistem yang penilaian yang diberlakukan selama ini sudah cukup efektif dalam meningkatkan pelayanan. Karena jika sistem penilaian kinerja dapat berjalan efektif maka permasalahan tersebut dapat didiagnosa sejak awal dan diharapkan dapat mengimplikasikan terhadap kebijakan kompensasi. 


\section{LANDASAN TEORI}

\section{Manajemen Kinerja Keperawatan}

Manajemen berasal dari bahasa inggris yaitu management yang merupakan bentuk nouns dari kata kerja to manage yang bermakna mengurus, mengatur, melaksanakan dan mengelola. Pengertian manajemen menurut Hasibuan dalam Wahyudi (2018), "manajemen adalah ilmu dan seni mengatur proses pemanfaatan sumber daya manusia dan sumber-sumber lainnya secara efektif untuk mencapai suatu tujuan tertentu" [14]. Menurut pendapat G.R. Terry dalam Sugiarti (2018) menjelaskan bahwa "manajemen merupakan suatu proses khas yang terdiri atas tindakan-tindakan perencanaan, pengorganisasian, penggerakan dan pengendalian untuk menentukan serta mencapai tujuan melalui pemanfaatan sumber daya manusia" [15].

Kinerja Keperawatan adalah aktivitas perawat dalam mengimplementasikan sebaik- baiknya suatu wewenang, tugas, dan tanggung jawabnya dalam rangka pencapaian tujuan tugas pokok profesi dan terwujudnya tujuan dan sasaran organisasi.

Penilaian Kinerja Keperawatan berdasarkan Instrumen Evaluasi Penerapan Standar Asuhan Keperawatan di Rumah Sakit. Penilaian instrumen dilakukan oleh tim Mutu Keperawatan, Instrumen A dilakukan dengan cara membandingkan pendokumentasian yang ditemukan dalam rekam medis pasien dengan pendokumentasian yang ditemukan ditentukan dalam standar asuhan keperawatan. Instrumen B dilakukan dengan cara memberikan angket ke pasien baik rwat inap atau rawat jalan untuk memberikan penilaian terhadap asuhan keperawatan yang telah diberikan, kriteriapasien rawat inap yang dievaluasi adalah sudah menjalani rawat inap tiga hari. Instrumen $\mathrm{C}$ dilakukan dengan cara membandingkan hasil observasi yang ditemukan dengan standar asuhan keperawatan, dan menggunakan SOP ilmu keperawatan.

Dengan demikian dapat disimpulkan bahwa Manajemen Konerja Keperawatan adalah suatu proses pengelolaan aktivitas keperawatan dalam melaksanakan tugas, wewenang dan tanggungjawabnya dimulai dari perencanaan, pengorganisasian, penggerakan dan pengendalian untuk menentukan serta mencapai tujuan organisasi melalui pemanfaatan sumber daya manusia secara efektif dan efesien.

\section{Kualitas Pelayanan}

Kualitas pelayanan adalah perbedaan antara harapan pelanggan akan suatu pelayanan dengan persepsi mereka akan pelayanan yang mereka terima. Saat harapan pelanggan lebih rendah dari persepsi terhadap pelayanan yang diperoleh, maka hal tersebut menjadi kejutan yang menyenangkan bagi pelanggan, pada saat harapan pelanggan sesuai dengan persepsi terhadap pelayanan yang diperoleh maka pelanggan akan merasa puas. Namun, pada saat harapan pelanggan lebih besar dari pada persepsi terhadap pelayanan yang diperoleh maka pelanggan tidak puas terhadap pelayanan [16].

1. Self awareness : Menanamkan kesadaran diri, menanamkan pelayanan dengan benar.

2. Reform : Memperbaiki kinerja pelayanan.

3. Value : Pelayanan dengan nilai tambah.

4. Impressive : Penampilan menarik. 
5. Care : Perhatian?kepedulian optimal.

6. Evaluation : Mengevaluasi layanan.

7. Self Esteem : Nilai pada diri sendiri.

8. Ekeed Expectation : Melampaui harapan pelangan.

9. Recover : Merebut kembali.

10. Vision : Visi.

11. Impower: Pemberdayaan.

12. Self Awarenees \& Self Esteem : Kesadaran dalam tugas dan menjaga maertabat diri dan pelanggan.

13. Empower : Pemberdayaan.

14. Vision \& Victory : Visi \& kemenangan semua pihak.

\section{Rumah Sakit}

Menurut Kamus Besar Bahasa Indonesia, definisi rumah sakit jiwa merupakan gedung tempat menyediakan dan memberikan pelayanan kesehatan khusus merawat orang yang memiliki gangguan kejiwaan.

Berdasarkan Peraturan Menteri Kesehatan Republik Indonesia Nomor 340/MENKES/PER/III/2010 tentang klasifikasi rumah sakit, rumah sakit jiwa adalah suatu lembaga yang memberikan pelayanan kesehatan khususnya kesehatan jiwa yang meliputi upaya yang bersifat Promotif (promosi), Preventif (pencegahan), Kuratif (penyembuhan), Rehabilitatif (pemulihan).

Rumah sakit jiwa memiliki upaya kesehatan jiwa bertujuan:

1. Memberikan pelayanan kesehatan khusus kesehatan jiwa bagi orang dengan gangguan jiwa.

2. Menghilangkan stigma, diskriminasi, pelanggaran hak asasi orang dengan gangguan jiwa sebagai bagian dari masyarakat.

3. Mencegah terjadinya masalah kejiwaan dan mengurangi faktor resiko akibat gangguan jiwa pada masyarakat secara umum atau perorangan.

4. Memberikan penyembuhan dan pemulihan terhadap orang dengan gangguan kejiwaan.

5. Memberikan rehabilitasi untuk mempersiapkan dan memberi kemampuan kepada orang dengan gangguan kejiwaan agar mandiri di masyarakat.

6. Memberikan kesempatan kepada orang dengan gangguan jiwa untuk dapat memperoleh haknya sebagai Warga Negara Indonesia.

\section{Balance Scorecard}

Balanced Scorecard berasal dari dua kata yaitu balanced (berimbang) dan scorecard (kartu skor), balanced (berimbang) berarti adanya keseimbangan antara performance keuangan dan non-keuangan, performance jangka pendek dan performance jangka panjang, antara performance yang bersifat internal dan performance yang bersifat eksternal. Balanced Scorecard menunjukkan adanya metode pengukuran kinerja yang menggabungkan antara pengukuran keuangan dan non keuangan [17].

Balanced Scorecard memakai tolak ukur kinerja keuangan dengan menggunaka metode value fo money yang merupakan konsep pengelolaan organisasi sektor yang mendasarkan pada tiga elemen utama, yaitu: Ekonomi : perolehan input dengan kualitas dan kuantitas tertentu pada harga yang terendah yang mendekati harga pasar. Ekonomi merupakan perbandingan input dengan input value yang dinyatakan dalam satuan moneter, Untuk melihat tingkat kepuasan pelanggan, Zeithaml dan Berry (1996) telah mengembangkan sebuah instrumen yang dinamakan Service Quality (servqual) yang terbukti mampu mengukur tingkat kepuasan pelanggan atas pelayanan yang mereka terima kedalam 5 dimensi yaitu [18]: 
1. Wujud fisik (tangibles), adalah penampilan fisik seperti: tempat pelayanan, sarana dan prasarana yang dapat dilihat langsung secara fisik oleh pelanggan.

2. Keandalan (reliability), yaitu kemampuan untuk memberikan pelayanan yang dijanjikan dengan tepat waktu dan memuaskan.

3. Daya tanggap (responsiveness), adalah kemampuan pegawai

untuk membantu pelanggan dan memberikan pelayanan dengan tanggap.

4. Jaminan (assurance), adalah pengetahuan dan keramahan pegawai yang dapat menimbulkan kepercayaan diri pelanggan terhadap organisasi.

5. Empati (emphaty), adalah ketersediaan pegawai perusahaan untuk peduli, memberikan perhatian pribadi kepada pelanggan dan kenyamanan dalam melakukan hubungan komunikasi yang baik dan memahami kebutuhan pelanggan.

Pada dasarnya perspektif bisnis internal adalah membangun keunggulan organisasi melalui perbaikan proses internal organisasi yang berkelanjutan, dan perspektif ini harus mampu menjawab pertanyaan kita harus unggul di bidang apa, serta bagaimana kita membangun keunggulan. Beberapa aspek yang dapat memberikan gambaran kinerja perspektif ini. Sarana dan prasarana, adalah variabel yang menggambar kondisi sarana dan prasarana yang dimiliki dalam mendukung kegiatan internal. Proses, maksudnya adalah untuk mengetahui tingkat kemampuan pegawai atas suatu rangkaian pekerjaan yang dilakukan dalam memberikan pelayanan publik. Kepuasan bekerja, adalah variabel yang menggambarkan tingkat kepuasan bekerja pegawai.

Perspektif pertumbuhan dan pembelajaran difokuskan untuk menjawab pertanyaan bagaimana organisasi terus melakukan perbaikan dan menambah nilai bagi pelanggan dan stakeholdersnya. Dengan demikian organisasi sektor publik harus berinovasi, berkreasi dan belajar untuk melakukan perbaikan secara terus menerus dan menciptakan pertumbuhan yang berkelanjutan.

\section{METODE PENELITIAN}

Penelitian ini termasuk penelitian kualitatif. Penelitian kualitatif bertujuan memperoleh gambaran seutuhnya mengenai suatu hal menurut pandangan manusia yang diteliti. Penelitian kualitatif berhubungan dengan ide, persepsi, pendapat atau kepercayaan orang yang diteliti dan kesemuanya tidak dapat diukur dengan angka, bersifat fenomenologis, yaitu mencoba menjelaskan atau mengungkap makna konsep atau fenomena pengalaman yang didasari oleh kesadaran yang terjadi pada beberapa individu, situasi yang alami, sehingga tidak ada batasan dalam memaknai atau memahami fenomena yang dikaji.

Populasi dalam penelitian ini ialah 4 orang. Pengambilan sampel dalam penelitian ini menggunakan teknik purposive sampling atau sampel bertujuan dengan kriteria.Direktur Utama, Ketua RSJ, HRD sekaligus sebagai Sekertaris Keuangan, dan 1 tenaga Perawat, bersedia untuk diwawancarai dan punya jabatan sesuai kriteria, dimana sampel yang diambil tidak menggunakan teknik bola salju (snowball sampling).

Tempat yang dilakukan penelitian adalah RSJ Anmarsu Hospice Care. Penelitian ini di laksanakan pada bulan Agustus -November 2020.

Instrumen atau alat yang digunakan dalam pengumpulan data penelitian ini adalah pedoman / panduan wawancara mendalam dan observasi data secara langsung terhadap dokumen yang disebutkan informan. Dalam penelitian ini, sesuai dengan objek penelitian maka, peneliti memilih observasi partisipan. Observasi partisipan yaitu suatu teknik pengamatan dimana peneliti ikut ambil bagian dalam kegiatan yang dilakukan oleh objek yang diselidiki. Observasi ini dilakukan dengan mengamati dan mencatat langsung terhadap objek penelitian, yaitu 
dengan mengamati kegiatan-kegiatan yang ada di rumah sakit. Sehingga peneliti dapat menentukan informan yang akan diteliti dan juga untuk mengetahui jabatan, tugas/kegiatan, alamat, nomor telepon dari calon informan sehingga mudah untuk mendapatkan informasi untuk kepentingan penelitian.

Dalam teknik pengumpulan data menggunakan wawancara hampir sama dengan kuesioner. Wawancara itu sendiri dibagi menjadi 3 kelompok yaitu wawancara terstruktur, wawancara semi-terstruktur, dan wawancara mendalam (in-depth interview).

Namun disini peneliti memilih melakukan wawancara mendalam, ini bertujuan untuk mengumpulkan informasi yang kompleks, yang sebagian besar berisi pendapat, sikap, dan pengalaman pribadi. Yaitu Teknik pengumpulan data yang dilakukan dengan mempelajari buku-buku referensi, laporan- laporan, majalahmajalah, jurnal-jurnal dan media lainnya yang berkaitan dengan obyek penelitian. Adapun analisis yang digunakan yaitu teknik analisis isi (content analysis) dengan menggunakan alat ukur Balance Scorecard.

\section{HASIL PENELITIAN DAN PEMBAHASAN}

\section{Tabel 1. Pendekatan terhadap keseluruhan pengukuran}

\begin{tabular}{cl}
\hline No & \multicolumn{1}{c}{ Indikator } \\
\hline 1 & Tolak ukur yang terdapat dalam database yang terhubung dengan key success factor, \\
& yang membedakan organisasi dengan kcompetitor. \\
2 & Data base di bangun secara terencana, tidak bersifat dadakan. \\
3 & CEO/Presdir mengevaluasi tidak lebih dari 20 tolak ukur setiap bulanya untuk \\
& mengevaluasi keseluruhan kinerja organisasi. \\
4 & Hampir keseluruhan tolak ukur kinerja konsisten dengan SBU. \\
5 & Organisasi memiliki satu set tolak ukur yang baik, yang seimbang antara kinerja \\
& keuangan, kinerja oprasional, kepuasan pelanggan, kepuasan pegawai, kualitas \\
produk atau jasa, kinerja pemasok, kinerja lingkungan/keamanan.
\end{tabular}

Sumber: Data penelitian, 2020

Hasil pengukuran indikator bagian I, pendekatan terhadap keseluruhan pengukuran diperoleh hasil sebesar 23 poin $\times 2$. Total yaitu 46 poin,

Tabel 2. Jenis Tolak Ukur Spesifik Yang Terhadap Dalam Organisasi Tolok Ukur yang Berhubungan dengan Pelanggan

\begin{tabular}{cll}
\hline No & & \multicolumn{1}{c}{ Indikator } \\
\hline 6 & Data base saat ini mencakup tolak ukur yang tepat mengenai kepuasan \\
& pelanggan/nilai pelanggan seperti bisnis yang merugi, laba, dan lain-lain. \\
7 & Organisasi yang mengumpulkan data kepuasan pelanggan dan tingkat penerimaan
\end{tabular}
pelanggan dengan menggunakan berbagai teknik seperti survei televon, survei surat dan grup-grup focus.

8 Survei kepuasan pelanggan yang dilakukan lebih difokuskan pada upaya menyenangkan pelanggan dari pada hanya untuk memuaskan pelanggan.

9 Hal-hal yang ditanyakan dalam survei/diskusi tentang kepuasan pelanggan, didasarkan pada riset untuk mengidentifikasikan kebutuhan pelanggan yang paling penting.

10 Organisasi menggabungkan berbagai variasi tolak ukur kepuasan pelanggan (soft and hard measure) ke dalam suatu indeks kepuasan pelanggan secara keseluruhan.

Sumber: Data penelitian, 2020

Tabel 3. Tolak Ukur Pegawai

\begin{tabular}{cc}
\hline No & \multicolumn{1}{c}{ Indikator } \\
\hline 11 & $\begin{array}{l}\text { Survei pelanggan dilakukan paling sedikit sekali dalam sentuhan untuk menentukan } \\
\text { tingkat kepuasan pelanggan dengan keseluruhan aspek organisasi. }\end{array}$ \\
12 & $\begin{array}{l}\text { Survei pegawai bersifat anonym dan lebih dari } 75 \% \text { kuesioner dikembalikan setiap } \\
\text { tahunnya. }\end{array}$ \\
13 & Organisasi melakukan riset untuk menentukan hal-hal penting bagi pegawai sebelum \\
\hline
\end{tabular}




\begin{tabular}{cl}
\hline No & \multicolumn{1}{c}{ Indikator } \\
\hline 14 & $\begin{array}{l}\text { survai standar dilakukan. } \\
\text { Organisasi menggumpulkan data berdasarkan matrik lain yang terkait gan tolak ukur } \\
\text { kepuasan pelangggan seperti absensi, tingkat sukarelawan, jam kerja per minggu, } \\
\text { permohonan mutasi, stress dll. }\end{array}$ \\
15 & $\begin{array}{l}\text { Tolak ukur individu terhadap kepuasan pegawai digabungkan kedalam indeks } \\
\text { kepuasan pegawai secara keseluruhan. }\end{array}$ \\
\hline
\end{tabular}

Sumber: Data penelitian, 2020

\section{Tabel 4. Tolak Ukur Keuangan}

\begin{tabular}{cl}
\hline No & \multicolumn{1}{c}{ Indikator } \\
\hline 16 & $\begin{array}{l}\text { Organisasi telah mengidentifikasi beberapa alat ukur kunci (4-6) dalam pengukuran } \\
\text { kinerja keuagan. }\end{array}$ \\
17 & $\begin{array}{l}\text { Tolak ukur keuangan merupakan suatu gabungan tolak ukur keuangan jangka pendek } \\
\text { dan jangka panjang. }\end{array}$ \\
18 & $\begin{array}{l}\text { Tolak ukur keuangan konsisten dengan keseluruhan unit/lokasi yang berbeda. } \\
19\end{array}$ \\
$\begin{array}{l}\text { Organisasi mengumpulkan keseluruhan data keuangan competitor utama untuk } \\
\text { mengevaluasi kinerja dan membuat berbagai tujuan organisasi. }\end{array}$ \\
$\begin{array}{l}\text { Organisasi menggabungkan keseluruhan data keuangan kedalam satu atau dua } \\
\text { ringkasan statistik yang merelefsikan keseluruhan kinerja seperti ekonimi value added } \\
\text { (EVA) atau return on assets (ROA). }\end{array}$ \\
\hline
\end{tabular}

Sumber: Data penelitian, 2020

\section{Tabel 5. Tolak Ukur Operasional}

\begin{tabular}{ll}
\hline No & \multicolumn{1}{c}{ Indikator } \\
\hline 21 & $\begin{array}{l}\text { Organisasi telah mengembangkan satu set tolak ukur oprasional yang terdiri dari 4-6 } \\
\text { tolak ukur seperti value added per pegawai yang digunakan dalam semua } \\
\text { fungsi/lokasi. }\end{array}$ \\
22 & $\begin{array}{l}\text { Beberapa tolak ukur proses yang dikumpulkan terkait langsung dengan karaakteristik } \\
\text { key produk/service yang menjadi perhatian pelanggan. }\end{array}$ \\
23 & $\begin{array}{l}\text { Cycle time digunakan sebagai tolak ukur kunci dalaam oprasional organisasi kunci. } \\
24\end{array}$ \\
& $\begin{array}{l}\text { Tolak ukur oprasional memungkinkan organisasi untuk mencegah timbulnya problem } \\
\text { dari pada hanya sekedar mengidentifikasi problem. }\end{array}$ \\
25 & $\begin{array}{l}\text { Organisasi telah membuat standar yang terukur untuk seluruh tolak ukur kunci dalaam } \\
\text { proses. }\end{array}$
\end{tabular}

Sumber: Data penelitian, 2020

\section{Tabel 6. Tolak Ukur Pemasok}

\begin{tabular}{ll}
\hline No & \multicolumn{1}{c}{ Indikator } \\
\hline 26 & Organisasi memiliki sistem pemeringkatan untuk mengevaluasi kinerja pemasok. \\
27 & $\begin{array}{l}\text { Sistem pemeringkatan pemasok merupakan gabungan data seperti tingkat } \\
\text { pengembalian produk barang yang rusaak, dan solf data seperti tingkat kepuasan }\end{array}$ \\
& $\begin{array}{l}\text { terhadap respon pemasok. } \\
28\end{array}$ \\
29 & $\begin{array}{l}\text { Organita prodk/jasa yang di beli dari pemasok diukur berdasarkan regular basis. } \\
\text { pelaksanaan inspeksi yang dilakukan sendiri. } \\
30 \\
\text { Mempertahankan price guidelines merupakan salah satu tolak ukur yang digunakan } \\
\text { untuk mengevaluasi dan memilih para pemasok. }\end{array}$ \\
\hline
\end{tabular}
Sumber: Data penelitian, 2020

\section{Tabel 7. Tolak Ukur Kualitas Jasa}

\begin{tabular}{cl}
\hline No & \multicolumn{1}{c}{ Indikator } \\
\hline 31 & Karakteristik jasa yang diukur adalah hal-hal yang paling penting bagi pelanggan. \\
32 & $\begin{array}{l}\text { Jika } 100 \% \text { jasa tidak dicek, maka sejumlah besar sampel dibutuhkan untuk } \\
\text { menyakinkan bahwa seluruh jasa telah memenuhi standar. }\end{array}$ \\
33 & $\begin{array}{l}\text { Peralatan pengukuran otomatis digunakan jika memungkinkan, untuk menghindari } \\
\text { kesalahan, yang disebabkan oleh poor human judgemen. }\end{array}$ \\
34 & Tolak ukur untuk jasa lebih dikaitkan dengan tingkat penyelesaian daripada prilaku \\
\hline
\end{tabular}




\begin{tabular}{cl}
\hline No & \multicolumn{1}{c}{ Indikator } \\
\hline $35 \quad \begin{array}{l}\text { (seperti persentase terpenuhinya sapaan, senyuman, pelayanan yang diberikan } \\
\text { kepada pelanggan). } \\
\text { Berbagai tolak ukur kualitas jasa lebih diganbarkan dengan angka-angka actual } \\
\text { daripada dalam bentuk persentase jasa. } \\
\text { 36 Organisasi mengumpulkan data-data pengukuran kinerja keamanan dan lingkungan } \\
\text { paling sedikit sekali dalam sebulan, dengan menggunakan beberapa tolak ukur yang } \\
\text { berbeda. } \\
\text { Organisasi melakukan pengukuran tingkat keamanan yang lebih bersifat behavior dan } \\
\text { prefentif. } \\
\text { Tolak ukur lingkungan yang digunakan didasarkan pada peraturan pemerintah. } \\
\text { Organisasi mengumpulkan data-data mengenai peraturan dan tolak ukur } \\
\text { pertanggungjawaban public seperti waktu pemberian layanan sosial/komunitas } \\
\text { maupun penghargaan yang diterima dari komunitas/kelompok sosial. } \\
\text { Organisasi telah mengembangkan suatu indeks pertanggung jawaban public yang } \\
\text { merupakan gabungan tolak ukur keamanan, lingkungan dan layanan sosial/komunitas. }\end{array}$ \\
\hline
\end{tabular}
Sumber: Data penelitian, 2020

Hasil pengukuran indicator bagian II, jenis tolak ukur spesifik yang terhadap dalam organisasi diperoleh hasil sebesar 140 poin.

Tabel 8. Pelaporan dan Analisis Data

\begin{tabular}{|c|c|}
\hline No & Indikator \\
\hline 41 & $\begin{array}{l}\text { Organisasi melaporkan data dari berbagai bagian ke dalam suatu laporan tunggal, } \\
\text { kepada seluruh manejer kunci. }\end{array}$ \\
\hline 42 & $\begin{array}{l}\text { Data digambarkan dalam bentuk grafik yang mudah dibaca dan dianalisis untuk } \\
\text { mengidentifikasi trend dan level kinerja organisasi. }\end{array}$ \\
\hline 43 & $\begin{array}{l}\text { Data kepuasan pelanggan, kepuasan pegawai dan inovasi/pertumbuhan ditinjau sering } \\
\text { mungkin oleh pihak eksekutif seperti halnya dengan data keuangan, operasional, jasa } \\
\text { dan kinerja pegawai. }\end{array}$ \\
\hline 44 & $\begin{array}{l}\text { Organisasi melakukan riset untuk mengidentifikasikan hubungan antara tingkat } \\
\text { kepuasan pelanggan dan kinerja keuangan. }\end{array}$ \\
\hline 45 & $\begin{array}{l}\text { Organisasi memahami hubungan antara berbagai tolak ukur kunci dalam keseluruhan } \\
\text { scorecard. }\end{array}$ \\
\hline 46 & $\begin{array}{l}\text { Data kinerja di analisis dan digunakan untuk membuat keputusan kunci mengenai } \\
\text { bisnis organisasi. }\end{array}$ \\
\hline 47 & $\begin{array}{l}\text { Berbagai tolak ukur kunci konsisten dengan misi, niali-nlai dan tujuan serta strategi } \\
\text { jangka panjang organisasi. }\end{array}$ \\
\hline 48 & $\begin{array}{l}\text { Organisasi secara terus menerus mengevaluasi dan memperbaiki tolak ukur dan } \\
\text { metode yang digunakan untuk menggumpulkan dan melaporkan data kinerja. }\end{array}$ \\
\hline 49 & $\begin{array}{l}\text { Alat ukur otomatis dan manual diselaraskan secara regular untuk menyakinkan akurasi } \\
\text { dan reabilitas data. }\end{array}$ \\
\hline 50 & $\begin{array}{l}\text { Tolak ukur dalam scorecard organisasi sama dengan tujuan jangka pendek dan jangka } \\
\text { panjang seperti yang telah ditetapkan selama proses perencanaan. }\end{array}$ \\
\hline
\end{tabular}
Sumber: Data penelitian, 2020

Hasil pengukuran indikator bagian III, pelaporan dan analisis data diperoleh hasil sebesar 48 poin x 2 . Total 96 poin.

Total hasil pengukuran keseluruhan dari tiga bagian yaitu diperoleh $46+140+$ $96=282$ poin.

Maka hasil tersebut dapat diinterpretasikan dengan hasil perhitungan skor berada pada kisaran nilai 276 hingga 325 yaitu yang berarti perusahaan dalam hal ini RSJ Anmarsu Hospice Care telah memiliki pendekatan yang sangat baik dalam mengukur kinerja organisasi. RSJ Anmarsu Hospice Care memiliki suatu data base yang ringkas yang terhubung dengan scorecard kunci dan juga memiliki satu set tolok ukur berimbang yang baik. RSJ Anmarsu Hospice Care juga terbukti dapat menggunakan 
data yang dikumpulkan untuk membuat keputusan dalam meningkatkan kinerja organisaasi. Dan RSJ Anmarsu Hospice Care dapat menjadi benchmark dalam suatu pengukuran.

\section{KESIMPULAN DAN SARAN}

Berdasarkan hasil analisis balance scorecard dan analisa data serta kajian teoretik yang ada, dapat dibuat kesimpulan sebagai berikut:

1. Hasil perhitungan Balance Scorecard didapatkan skor 282 poin yang berarti bahwa RSJ Anmarsu Hospice Care telah memiliki pendekatan yang sangat baik dalam mengukur kinerja keperawatan dan kinerja organisasi.

2. RSJ Anmarsu Hospice Care sudah memiliki suatu data base yang ringkas yang terhubung dengan scorecard kunci dan juga memiliki satu set tolok ukur berimbang yang baik dalam meningkatkan kualitas pelayanan terhadap pasien.

3. RSJ Anmarsu Hospice Care juga terbukti dapat menggunakan data yang dikumpulkan untuk membuat keputusan dalam meningkatkan kualitas pelayanan terhadap pasien. Untuk itu RSJ Anmarsu Hospice Care dapat menjadi benchmark dalam suatu pengukuran.

Berdasarkan kesimpulan dan implikasi, peneliti memberikan beberapa saran sebagai berikut :

1. Dari segi pelayanan, RSJ Anmarsu sudah menerapkan sistem evaluasj karyawan setiap minggunya, hal ini sudah cukup baik tetapi sebaiknya evaluasi dilakukan lebih terarah dan terdokumentasi. Sebagai contoh pada saat dilakukan evaluasi, ada pihak yang mencatat masalah yang timbul saat itu, tindakan apa yang akan dilakukan, dan apakah tindakan tersebut dilaksanakan yang nantinya akan dievaluasi ulang mungkin dalam kurun waktu 2 minggu atau 1 bulan cukup. Selain itu, bisa pula diadakan reward bagi karyawan yang disiplin dan bersedia untuk menindaklanjuti kondisi masalah tersebut sehingga terciptanya peningkatan pelayanan di RSJ Anmarsu Hospice Care.

2. Selain itu, ada beberapa kelemahan yang bisa diminimalisir seperti untuk meningkatkan sistem kerjasama dibidang perujukan. Sejauh ini Anmarsu memiliki beberapa RS rujukan yang sudah berjalan, namun hal ini bisa ditingkatkan dengan cara membukukannya secara tertulis, agar siapapun yang bertugas dapat memutuskan dengan cepat apabila ada kondisi darurat atau emergency yang terjadi pada pasien di RSJ Anmarsu Hospice Care. Dari segi SOP dan SAK pun meskipun sudah ada dan tertulis, perlu dilakukan secara praktis, update, pengaplikasian dan evaluasi minimal setahun sekali, hal ini dilakukan untuk menilai apakah SOP dan SAK yang ada dapat diterapkan dengan baik di RSJ Anmarsu Hospice Care atau perlu penyesuaian ulang agar terciptanya peningkatan pelayanan yang ada di RSJ Anmarsu Hospice Care.

3. Berdasarkan perhitunganan tenaga keperawatan menurut Dinkes dapatkan hasil bahwa jumlah ideal tenaga perawat di RSJ Anmarsu Hospice Care sebaiknya berjumlah 7 perawat, sedangkan berdasarkan hasil penelitian yang dilakukan penulis jumlah tenaga perawat di RSJ Anmarsu Hospice Care masih belum mencukupi standarnya.Ppenulis menyarankan untuk RSJ Anmarsu Hospice Care agar dapat menambahkan jumlah tenaga perawatan agar bisa meningkatkan kualitas pelayanan yang ada di RSJ Anmarsu Hospice Care. 


\section{DAFTAR PUSTAKA}

[1] Rini, R. S., \& Wijayanti, M. (2018). Frontliner Services In PT KAI Commuter Jabodetabek New Klender Station, East Jakarta. SCIENTIFIC JOURNAL OF REFLECTION: Economic, Accounting, Management and Business, 1(3), 331-340.

[2] Tisu, L., Lupșa, D., Vîrgă, D., \& Rusu, A. (2020). Personality characteristics, job performance and mental health: the mediating role of work engagement. Personality and Individual Differences, 153, 109644.

[3] Anggraeni, F. N. (2020). DETERMINAN MOTIVASI INTERNAL TERHADAP KINERJA. SCIENTIFIC JOURNAL OF REFLECTION: Economic, Accounting, Management and Business, 3(2), 161-170.

[4] Harras, H., Sugiarti, E., \& Wahyudi, W. (2020). Kajian Manajemen Sumber Daya Manusia Untuk Mahasiswa.

[5] Niessen, C., \& Lang, J. W. (2020). Cognitive control strategies and adaptive performance in a complex work task. Journal of Applied Psychology.

[6] Shin, Y., Hur, W. M., \& Choi, W. H. (2020). Coworker support as a double-edged sword: A moderated mediation model of job crafting, work engagement, and job performance. The International Journal of Human Resource Management, 31(11), 1417-1438.

[7] Papay, J. P., Taylor, E. S., Tyler, J. H., \& Laski, M. E. (2020). Learning job skills from colleagues at work: Evidence from a field experiment using teacher performance data. American Economic Journal: Economic Policy, 12(1), 359-88.

[8] Mathodah, S. (2018). Teachers Performance Analysis Of Vocation High School In Banten Province. Scientific Journal of Reflection: Economic, Accounting, Management and Business, 1(2), 181-190.

[9] Wahyu, W., \& Salam, R. (2020). KOMITMEN ORGANISASI (Kajian: Manajemen Sumber Daya Manusia).

[10] Rasool, S. F., Wang, M., Zhang, Y., \& Samma, M. (2020). Sustainable work performance: the roles of workplace violence and occupational stress. International journal of environmental research and public health, 17(3), 912.

[11] Gopinath, R. (2020). ROLE ON EMPLOYEES'ATTITUDE IN WORK PLACE.

[12] Loan, L. (2020). The influence of organizational commitment on employees' job performance: The mediating role of job satisfaction. Management Science Letters, 10(14), 3307-3312.

[13] Sunarto, A. (2018). Hubungan Stres Kerja dan Prestasi Kerja Karyawan PT. Asuransi Sinarmas Jakarta Pusat pada Divisi Credit Control. SCIENTIFIC JOURNAL OF REFLECTION: Economic, Accounting, Management and Business, 1(4), 361-370.

[14] Wahyudi, W. (2018). The Influence of Emotional Intelligence, Competence and Work Environment on Teacher Performance of SMP Kemala Bhayangkari Jakarta. SCIENTIFIC JOURNAL OF REFLECTION: Economic, Accounting, Management and Business, 1(2), 211-220.

[15] Sugiarti, E. (2018). Building Work Commitment of Bppt Employee. SCIENTIFIC JOURNAL OF REFLECTION: Economic, Accounting, Management and Business, 1(2), 171-180.

[16] Hong, S. J., Choi, D., \& Chae, J. (2020). Exploring different airport users' service quality satisfaction between service providers and air travelers. Journal of 
Retailing and Consumer Services, 52, 101917.

[17] Fatima, T., \& Elbanna, S. (2020). Balanced scorecard in the hospitality and tourism industry: Past, present and future. International Journal of Hospitality Management, 91, 102656.

[18] Frederico, G. F., Garza-Reyes, J. A., Kumar, A., \& Kumar, V. (2020). Performance measurement for supply chains in the Industry 4.0 era: a balanced scorecard approach. International Journal of Productivity and Performance Management. 